\title{
Investigating Attributes for Performing Quality Analytics in Web Learning Environment
}

\author{
Rohini Arora \\ Research Scholar \\ Department of Computer Science and Applications \\ Panjab University, Chandigarh India
}

\author{
Indu Chhabra, PhD \\ Professor \\ Department of Computer Science and Applications \\ Panjab University, Chandigarh, INDIA
}

\begin{abstract}
Quality is directly connected with satisfaction of the user and one will satisfy providing the training surroundings which provides full technical, infrastructure support and interactive user interface. Quality Analytics is that the discovery and also the systematic machine analysis of knowledge statistics to search out meaningful patterns particularly valuable in areas wealthy with recorded information. Quality Analytics of web application surroundings evaluates the appliance supported varied relevant quality parameters like Business Qualities, Generic Qualities, System Qualities and Learner Response Qualities. These parameters should be targeted upon to style analytical pattern to watch the user behavior. If any of the web-based application fails to deliver these then it clearly reflects the compromise within the quality of the merchandise. ISO/IEC 19796-1 international customary focuses on quality management and assurance in e-Learning and it's also necessary to scrutinize and assess the results generated by various quality factors in dynamic net based environment. This paper proposes analytics based mostly technique to generate and monitor values of some vital quality factors. Effective assessment of those factors is useful in standardization the overall performance of dynamic net based surroundings and the analytics make sure the user behavior towards the web application.
\end{abstract}

\section{General Terms}

Web Applications, Quality Attributes, Quality Analytics.

\section{Keywords}

Quality Analytics, Quality Components, Web Environment, Information Process Model.

\section{INTRODUCTION}

Web applications of any area of e-services, information sharing, inventory, education etc., has undergone intensive development as associate degree inevitable results of the recent proliferation of net technology. e-Learning is one of the most popular area in which thousands of users/learners are finding the web resources for the useful information retrieval. Ancient means that of learning prohibit the learner to sure learning ways, at a selected time and place whereas e-learning services produce wider horizons for organizations and people United Nations agency square measure concerned in teaching and learning. These environments facilitate the delivery of considerable components of education through the employment of tools and materials that square measure accessible directly to the learners' home or workplace, and at any time. Additionally, the advancements in technology, that square measure want to enhance the interactivity and media content of the online and therefore the increasing quality of delivery platforms, produce a perfect setting for the enlargement of e-learning systems. However, issues may arise as a result of the outstanding increased reliance on e-learning systems at completely different levels across education. The growing variety of accessible e-learning systems and therefore the commercialization of those systems highlight the need of quality evaluations of on-line revealed learning materials. Though quality analysis of learning materials in e-learning systems became more and more vital, the actual analysis standards and ways for information quality (IQ) in such systems haven't however reached a accord. What is more, criteria and ways utilized to gauge e-learning materials and systems ought to have specific characteristics that take issue from the methods want to measure typical learning materials. To resolve this problem, comprehensive and specific quality criteria square measure required to develop a reliable measuring technique for this type of data (Bozula \&amp; Morgun, 2008). Moreover, the required context and the views of the users have to be compelled to be thought-about once shaping quality in associate degree e-learning context. It's additionally vital to outline acceptable criteria to explain quality (Stracke, 2007).

Quality assurance within the dynamic setting is the need of the hour. It is achieved with the assistance of applicable quality analytics. So as to possess the standard analytics for the given net learning setting it's necessary to trace the given application. Trailing is useful to grasp the dynamic behavior of the appliance and also the analytics give the results of continuous watching as knowledge patterns [5], [6]. The processing of knowledge patterns is tedious process as they are helpful for the further evaluation of quality analytics pattern. Data visualization through these patterns is helpful to possess insight into the dynamic setting. At now of your time quality is examined and warranted as per the parameters promised at the time of choice. These analytics will additionally useful to tune the performance of the appliance.

\section{ANALYSIS OF QUALITY COMPONENTS}

There area unit range of Learning Management Systems (LMS) and Learning Content Management Systems (LCMS) frameworks to style and implement e-learning applications and services for learners. There is no pre outlined criteria to select the simplest appropriate framework for any given application domain. Choice of specific learning management system and content management system can have an effect on the standard of the product in addition because the service. eLearning applications give education to the learners through technology [8], [9]. The first focus of e-learning service is to meet the wants of learner keeping in sight the quality of content, service and delivery. e-Learning applications targets students as their users and therefore the domain in which the appliance deals is that the course structure and content related to it. Once the lectures, analysis material and lessons are provided to the learner through e-technology then quality of 
the education is set through the success rate of varied factors like delivery of right contents in optimum time in addition as in correct type and comprehensible manner. This paper proposes an analysis of varied factors touching the standard of web application. These factors area unit selected on the idea of its major purposeful elements [Fig. 1] demonstrating its key attributes of guaranteeing the supply of fine learning resource, fulfilling learner's wants and proving and guaranteeing the merchandise quality. Figure one illustrates that quality analysis and assurance should be processed on the idea of input provided by the learner to satisfy the simplest satisfaction level.

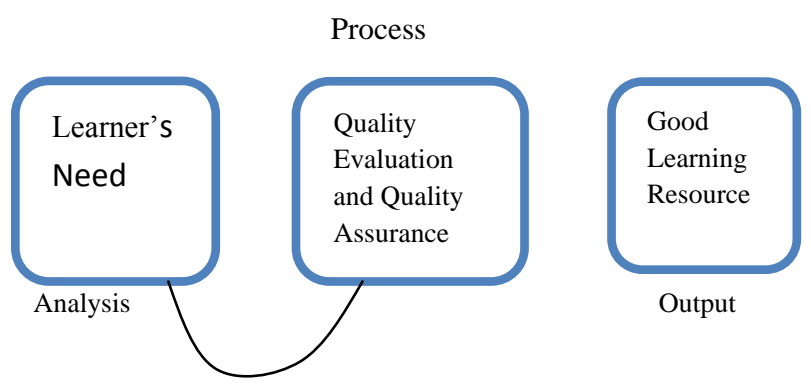

Fig 1: Information Process Model

In order to spot and analyze the fundamental mechanism contributing within the quality of the web-based e-learning application, it's continuously vital to grasp the fundamental framework and also the overall functioning of that application. There square measure many varieties of qualities that square measure to be ensured to measure the general quality of the merchandise like Business Qualities, Generic Qualities, System Qualities and Learner Response Qualities. to confirm the standard, the varied parts are projected, analyzed and evaluated within the literature [10], [11], [12], [13].

Quality is made on the flexibility to satisfy the satisfaction of the learner. Learner will solely satisfy if the applying selected can provide quality teaching and learning surroundings with full technical and infrastructure support and interactive user interface. Quality content continuously reflects the experience level of the teacher and quality of education additionally [14]. The parameters behind the contribution of quality providing factors square measure as follows.

a) Pedagogical Practices: These practices concerned quality of curriculum style, quality of its content, practicability of curriculum and also the practices concerned in the complete tutorial method.

b) Technological Standards: Quality is checked on the basis of measurability, stability and easy use of e-learning platform and most significantly sort of technical support provided to the learner on timely basis.

c) Interface Design: during this element the standard parameter is delivering the content in excellent frame which suits the learner the foremost counting on learner's talent.

d) Analysis Criteria: it's the foremost vital issue by which the abilities and skill of learner are often best judged by the applying. The perfection of evaluation criteria for evaluating performance, skill, assignments and tests. Another vital parameter under this element is evaluating feedback provided by the user. This parameter clears the steps followed by the applying to figure on the positive and feedback by the learner. e) Management info System: It covers parameters like quality of designing and management of learning operations, student management and every one e-operations associate with internet base e-learning application.

f) Resource Management and Delivery: Key parameters under this element associated with the standard square measure methods opted for management of all the e-resources and delivery procedures opted to supply facilitate and support to the learner. It additionally deals with the potency of content delivery system and support.

g) Moral Standards: Ethics deals with approach during which application commits to its terms and conditions. If application conforms to its work, teaching learning the publishing ethics then it directly reflects to its quality.

h) Institutional Development: during this element quality is measured on the premise of satisfaction of the institution. Experience and qualification of consultants delivering courses, their affiliations and technical support. The parameter to live this issue is additionally possible through rank and name of the establishment providing e-learning. Institution's name is that the first impact parameter carried by the learner whereas selecting any on-line course.

i) Infrastructure Support: Quality underneath this element can be judged supported the parameter of handiness of current infrastructure and also the infrastructure required to implement, give and to run any relevant learning surroundings. This parameter decides the price factors of any web-based e-learning application. Price is that the factor to draw in the students to avail the net course. When infrastructural necessities square measure a lot of it adds up to the cost of the course additionally and thence contributes within the quality.

j) Learner's Feedback System: This element takes and manages the learner's feedback. The ways and ways followed to take care of the feedback decide its quality. Moreover, it's vital parameter to gauge the actions taken by the application to satisfy the learner if feedback is negative.

k) Content Management System: The last and also the most important element is that the CMS. Its quality contributes within the overall quality of the whole product and its services. Potency of storage and content retrieval mechanisms contributes to the robustness of the online application. The key parameters here square measure content management, content personalization, backup and recovery ways and delivery ways opted.

\section{MEASUREMENT SCHEME AND EQUATIONS}

The metrics once identified act as roadmap for the analysis and prediction of quality data patterns. After investigating the metrics from mentioned attributes, the next step, associate degree use them to assess the ratio in an e-learning context. We have a tendency to use a multi element analysis technique to succeed in an overall quality score for the provided data (Gilb, 1977). 


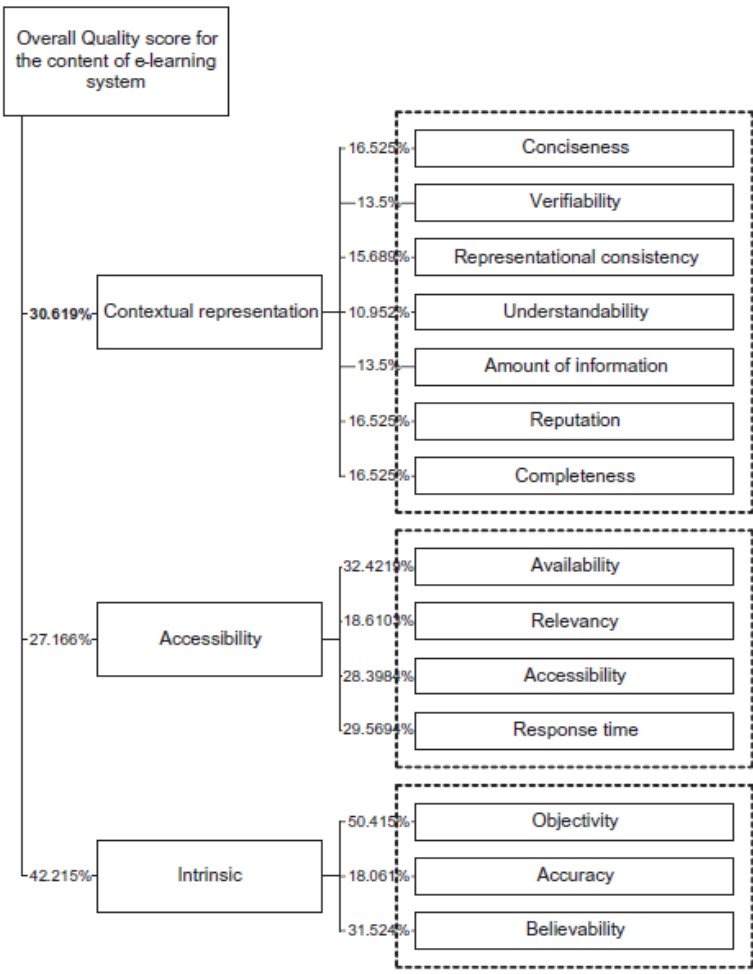

Fig 2: Information quality framework

\subsection{The multi-element analysis technique}

This technique was first off planned by the man of science Zangerneister in 1970; since then, the strategy has been with success used as a system analysis technique and it had been additionally referred to within the assessment of software system maintenance tools (Khan, 2008). Moreover, this system was with success utilized by Magnavox Electronic Systems Company (1990) in their analysis of software system development environments for version one of the Advanced Field Artillery plan of action information system (Buvaneswari, Venkataraman, \&amp; Ward, 1999).

To apply this methodology, 3 basic options ought to be presented: a graded organisation of quality attributes/classes, a proportion weight for these attributes, and a numeric evaluation for the final attributes/subclasses (Kahn \&amp; Ramakrishnan, 1997). The method depends on a graded organisation of quality attributes/classes and therefore the proportion weights for these attributes. For each attribute/class throughout the development, a proportion weight ought to be determined. the ultimate attributes/classes are assigned numeric scores to live their performance. The methodology for computing scores victimization this system starts by assignment weights to all or any of the kid nodes of every parent node within the attribute hierarchy. Then, scores ought to be allotted to the leaf nodes and therefore the allotted weights area unit accustomed propagate quality scores to the foundation (Buvaneswari et al., 1999). Intuitively, for all the kid nodes of every parent node the total of the weights should add up to a hundred (Khan \&amp; dynasty, 2006). Since the essential 3 elements to use this system are already provided by our planned framework, we have a tendency to determined to adopt this system to outline the measuring theme and calculate the overall IQ score in associate degree e-learning context.

\subsection{Definition of The Measuring Theme For Data Quality}

The idea of victimization the relative importance as a parameter for the measurement is vital since it provides the framework the flexibility to be adopted and employed in completely different e-learning environments and with completely different e-learning users, as a result of the importance weights may be changed if a high quality attribute or issue seems to no longer hold an equivalent significance for the standard assessment. In the planned framework 3 main quality factors were identified, and every issue consisted of variety of quality attributes (14 in total). We have a tendency to additionally allotted a relative importance weight for each attribute within the most quality factors, and a relative importance weight for every attribute consider the quality score. The percentages of the weights of all attributes within every factor add up to 100 percent, as shown in Fig. 2. within the same method, accumulated proportion weight of the standard factors would be always $100 \%$. These identified quality factors, quality attributes and the associated metrics, which were developed in the last section, are mapped into a measurement scheme along with the assigned relative importance weights of quality factors and attributes.

\section{QUALITY ANALYTICS}

Quality analytics is that the information analytics within which the information patterns fashioned area unit the values of these parameters that area unit contributing within the quality assessment and assurance of the given application [11], [12]. Analytics is that the four step method as shown in Fig. 1. These four steps embrace prediction, monitoring, analysis and reportage. Prediction deals with short listing of the parameters to be analyzed. This prediction is that the base for the right baseline for developing smart quality analytics. These foreseen parameters and monitored for the fixed time domain to possess an information pattern of values. The values are captured then intensively analyzed. Analytics application runs parallel with the training net application to be tracked. These trailing results area unit analytics which supplies the clear image relating to the dynamic behavior of the training application furthermore as learner's behavior. Analytics gathers the information patterns that area unit helpful type recording info of dynamic learning surroundings to optimization of the applying for rising its performance wherever potential as foreseen by the analytics. Analytics of gathered information is distributed at four levels as Descriptive, Diagnostic, prognostic and Prescriptive analytics [13]. Descriptive analytics provides this info concerning the dynamic surroundings that's what happened within the current scenario. In Diagnostic analytics the values area unit diagnosed to identify the explanations for the results generated. Betting on the available pattern future actions is foreseen in prognostic analytics to guess what is going to happen and at last in prescriptive analytics associate action arrange are framed so as to form some conditions or actions to happen. Learners within the learning environment use internetworking approaches to attach to the web application. Their behavior is half-track exploitation trailing tools and analytics tool to assemble the information patterns for the primary selected element underneath study which has main parameters to be analyzed as navigation, orientation and learning trailing. The whole info on process gives the learners behavior and application behavior on learner's actions. 


\section{CONCLUSION}

The increasing quality of e-learning materials and distance education raises the importance of quality assurance of elearning curriculum. This study thought of the follow of elearning courseware quality certification. We have a tendency to found that the analysis tool used for certification (the eLCQC) exhibits satisfactory dependability, item-difficulty and item-discrimination indices. Producers of e-learning courseware usually face difficulties once designing the teaching ways, assessments and learning methods to be incorporated into educational goals of the courseware. The entire method of certification which incorporates selfevaluation, committee interviews and post-review consultation, improves the courseware producers' conception of courseware style and implementation, and enhances their aggressiveness and confidence in soliciting customers.

\section{REFERENCES}

[1] Rohini, Indu Chhabra, 2014, "Quality Analytics for Evaluation of Dynamic Web Based Learning Environment"

[2] Rohini Arora, Indu Chhabra, 2013, "Extracting Components and Factors for Quality Evaluation of eLearning Applications"

[3] Yao-Ting Sung, Kuo-En Chang, Wen-Cheng Yu, 2011, "Evaluating the reliability and impact of a quality assurance system for E-learning courseware", Computers \& Education, 57, pp: 1615-1627

[4] Mona Alkhattabi, Daniel Neagu, Andrea Cullen, 2011, "Assessing information quality of e-learning systems: a web mining approach", Computers in Human Behavior, 27, pp: 862-873

[5] Wu, J.H., Tennyson, R.D. and Hsai, 2010, "A study of student satisfaction in blended e-learning system environment", Computer and Education, vol. 55, issue 1, pp.:155-164
[6] Garcia E., Cabot A.G., Karhu, 2012, “Analysis of standards and specification of quality and accessibility in e-learning”, ATICA, pp: 78-81.

[7] Nanduri, Babu, Jain, Sharma V.,Garg V., Rajshekhar, Rangi V., 2012, “ Quality Analytics Framework for ELearning Application Environment", IEEE Fourth International Conference on Technology for Education, pp: 204-207

[8] Wu H. Y., Lin H.Y., 2012, "A hybrid approach to develop an analytical model for enhancing the service quality of e-learning", Computers and Education, vol. 58, pp: $1318-1338$

[9] Suag, Y.T., Chang, K.E.,\& Yu, 2011, "Evaluating the reliability and impact of quality assurance system for elearning courseware", Computer \& Education, vol. 57, issue 2, pp. 1615-1627.

[10] Selim, H.M, 2007, "Critical success factors for elearning acceptance: Confirmatory factor models", Computer and Education, Vol. 49, issue 2, pp: 396-413.

[11] D. A. Menase, "QoS Issues in Web Services", IEEE Internet Computing, vol. 6, issue 6, December 2002, pp: 72-75.

[12] Pei- Chen Sun and Ray J. Tsai and Glenn Finger and Yueh-Yang Chen and Dowming Yeh, 2008, "What drives a successful e-Learning? An empirical investigation of the critical factors influencing learner satisfaction", Computers and Education, vol. 50, issue 4, pp: 1183-1202.

[13] Kaisler S.H., Armor, 2014, "Advanced Analytics Issues and Challenges in a Global Environment", proceedings of $47^{\text {th }}$ International Conference of HIISS, pp: $729-738$ 